\title{
New Director Named to Federal Acid-Rain Program
}

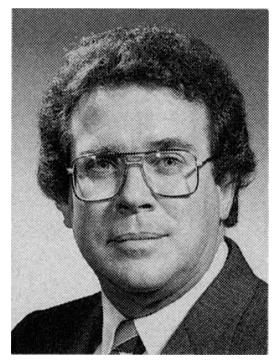

The Joint Chairs Council of the Interagency Task Force on Acid Precipitation has announced the designation of James R. Mahoney, of California, to be the new director of the National Acid Precipitation Assessment Program (NAPAP). Mahoney has served as a presidential appointee to the Task Force since 1982. He succeeds J. Laurence Kulp.

NAPAP is a federally funded 10-year research and assessment program established by the Acid Precipitation Act of 1980 . It is implemented by the Interagency Task Force on Acid Precipitation and is jointly chaired by the administrator of the U.S. Environmental Proctection Agency, the administrator of the National Oceanic and Atmospheric Administration, and appointees from the Department of Agriculture, the Department of Energy, the Department of the Interior, and the chairman of the Council on Environmental Quality. Representatives of six other federal agencies, the four National Laboratories, and four presidential appointees also serve on the Task Force. In September 1987 NAPAP published its Interim Assessment of the Causes and Effects of Acidic Deposition. It will prepare its Final Assessment in 1990.

Mahoney, 49, an environmental-management consultant, received his doctorate degree in meteorology from the Massachusetts Institute of Technology, and was a memeber of the faculty of Harvard University's Department of Environmental Health Sciences until 1973. He was a co-founder of Environmental Research and Technology, Inc. and served as senior vice-president until 1983. From 1984 to 1987 he was with the Bechtel Group, Inc. He is the author of more than 50 scientific and professional papers dealing principally with air pollution assessment and control, and has served on committees of the National Academy of Sciences. He has been an editor of the Journal of Applied Meteorology, an AMS councilor (19841987), and a member of the AMS Executive Committee (19851987).

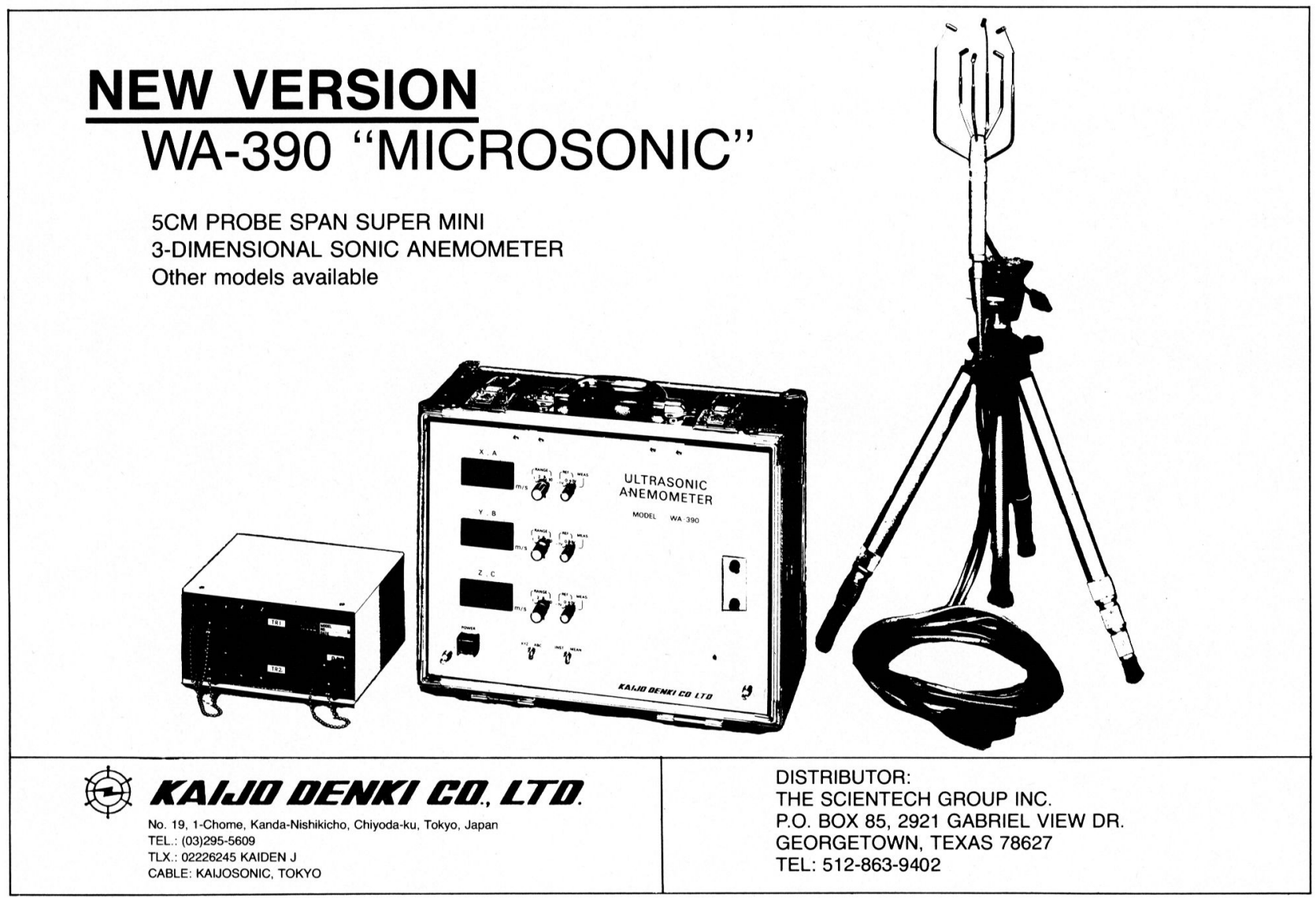


